\title{
Knowledge and Practices on the Safe Handling of Cytotoxic Drugs Among Oncology Nurses Working at Tertiary Teaching Hospitals in Addis Ababa, Ethiopia
}

This article was published in the following Dove Press journal:

Drug, Healthcare and Patient Safety

\author{
Selamawit Asefa' \\ Fekadu Aga $\mathbb{D}^{2}$ \\ Negalign Getahun Dinegde (D) ${ }^{2}$ \\ Takele Gezahegn Demie (iD) ${ }^{3}$ \\ 'Oncology Unit, Tikur Anbessa \\ Specialized Hospital, Addis Ababa, \\ Ethiopia; ${ }^{2}$ School of Nursing and \\ Midwifery, College of Health Sciences, \\ Addis Ababa University, Addis Ababa, \\ Ethiopia; ${ }^{3}$ Department of Public Health, \\ St. Paul's Hospital Millennium Medical \\ College, Addis Ababa, Ethiopia
}

Background: Cytotoxic drugs (CDs) administration and occupational exposure is a worldwide concern. Inappropriate handling may cause toxic residues to infiltrate hospital environments and patient care areas, and can even be traced to patients' homes. Hence, the study sought to assess knowledge and practices on the safe handling of cytotoxic drugs Among Oncology Nurses at Tertiary Teaching Hospitals in Addis Ababa, Ethiopia.

Methods: The researchers conducted a hospital-based cross-sectional study among 77 nurses from April 1-30, 2019. Purposive sampling was used in recruiting the respondents. Structured questionnaires were filled through self-administered interviewing. Data were analyzed using SPSS version 23 software. Multiple linear regression was performed to see the association between dependent variables and independent variables at a p-value of less than 0.05 .

Results: Mean score of knowledge and practice of nurses was $7.82 \pm 2.22$ out of 15 and 22.1 \pm 5.50 out of 40 respectively. Nearly $69 \%$ of nurses reported the lack of training program on the handling of CDs at their workplaces and the use of Personal Protective Equipment (PPE) remains suboptimal as none used all of PPE. Nurses who had not heard about CDs had an average knowledge score of 0.33 points lower than nurses who had heard about CDs ( $p \leq$ 0.01 ). Nurses who have scored higher knowledge points had 0.33 points more practice score of safe CD handling than those who had lower knowledge score $(\mathrm{p}<0.05)$ and also married nurses had average safe CDs handling practice score 0.27 points lower than their counterparts $(\mathrm{p}<0.05)$.

Conclusion: Nurses' knowledge and practice of safe handling of cytotoxic drugs are inadequate. Nurses who have scored higher knowledge points and are married were more likely to practice safe CD handling. Provision of proper PPE and training regarding the handling of CDs for Oncology Nurses are recommended and chemotherapy safety protocol and guidelines should be established.

Keywords: cytotoxic drugs, safe handling, knowledge, practice, oncology nurses, Ethiopia

\section{Introduction}

According to Global Cancer Incidence Mortality and Prevalence (GLOBOCAN) estimates, about 14.1 million new cancer cases, and 8.2 million deaths occurred in 2012 worldwide. ${ }^{1}$ However, there are an estimated 18.1 million new cases and 9.6 million deaths in $2018 ;^{2}$ new cases are expected to rise to 16 million by $2020 .^{3}$
Demie

Department of Public Health, St. Paul's Hospital Millennium Medical College, PO Box 127I, Addis Ababa, Ethiopia Tel +25I 912-I3605I

Email takele.gezahegn@sphmmc.edu.et

Drug, Healthcare and Patient Safety 2021:13 7I-80 
Cancer is expected to rank as the leading cause of death and the single most important barrier to increasing life expectancy in every country of the world in the 21 st century. ${ }^{2}$ Cancer constitutes an enormous burden worldwide that is expected to increase due to different factors known to cause cancer. ${ }^{1}$ Cancer is an emerging public health problem in Africa and about 715,000 new cancer cases and 542,000 deaths occurred in 2008, with these numbers expected to double in the next 20 years. ${ }^{4}$ In Ethiopia, annual incidence and mortality of all cancer were reported 51,700 and 41,600 respectively. ${ }^{5}$ Besides, cancer is responsible for $5.8 \%$ of total national deaths. ${ }^{6,7}$ According to GLOBOCAN 2012 estimates, about $40 \%$ of cancers are preventable. ${ }^{1}$

Cytotoxic drugs (CDs) are also known as antineoplastic, anticancer or cancer chemotherapy drugs include a wide range of chemical compounds. They are extensively used to treat cancer due to their ability to destroy tumor cells by interfering with cell division. ${ }^{8}$ Cytotoxic drugs can be classified into several subgroups depending on their chemical structure and pharmacodynamics of drugs; alkylating agents, antimetabolites, antitumor antibiotics, topoisomerase inhibitors, mitotic inhibitors, and miscellaneous. ${ }^{8} 9$ Widespread use of chemotherapy in the treatment of cancer has led to higher health hazards among nurses who handle and administer such drugs, so nurses should know how to protect themselves from the effects of chemotherapy. ${ }^{10,11}$ Safety concerns have existed for more than 40 years about how hazardous drug exposure contributes to long- and short-term adverse health outcomes for healthcare workers. Careless handling may cause toxic residues to infiltrate hospital environments and patient care areas, and can even be traced to patients' homes. ${ }^{12}$

Cancer chemotherapy administration is a complex medical procedure. It requires high levels of competency and safety to prevent errors that may cause harm to patients and staff. ${ }^{12,13}$ However, chemotherapy is still the main treatment regimen of cancer, and approximately $50 \%$ of patients with cancer receive chemotherapy. ${ }^{3}$ Numerous CDs were known to be carcinogenic, mutagenic, and teratogenic. Inappropriate handling and use of these drugs lead to occupational health hazards among workers in cancer management settings. ${ }^{9,14-18}$ Nurses are the main groups that are exposed to CDs in hospital settings having occupational activities that pose the greatest risk of exposure including preparation and administration of CDs, cleaning of CDs spills and handling of patient excreta. ${ }^{19-21}$
Occupational exposure CDs and related waste may occur during preparing, administering, transporting, and storing drugs and when handling cytotoxic waste, transporting and disposing of waste, and cleaning up spills. Exposure may occur through skin absorption, inhalation of aerosols and drug droplets, eye contact through a splash of liquids, ingestion, and sharps stick injury. ${ }^{9,16,20,22}$ Occupational exposure to cytotoxic drugs is a worldwide concern. ${ }^{23}$ Nurses who are exposed to CDs have reported acute health effects such as hair loss, skin rash, eczema, skin flush, lightheadedness, nausea, dizziness, and vomiting, and gastro intestine symptoms. ${ }^{9,16,19,23-27}$ Among the possible reproductive side effects experienced by exposed nurses were infertility, abortion, and abnormalities in fetuses. ${ }^{9,19,22,26,27}$

Safe handling of CDs is a monumental aspect of cancer management since these drugs have been identified as hazardous drugs. ${ }^{16}$ Knowledge is critical to safe nursing practice in all settings, but it is especially very important when handling CDs because knowledge deficit about these CDs handling may threaten personal safety or the safety of the patient. ${ }^{18,22,28-30}$ Also, unsafe or poor handling practices are indicated in several studies. ${ }^{10,11,17,22,24}$ Inconsistent use of personal protective equipment (PPE) was reported by different studies conducted elsewhere. $^{18,23,25,31}$

In Ethiopia, there is no published research concerning the knowledge and practice of Oncology Nurses on the safe handling of CDs until we conducted this study. Hence, this study sought to assess knowledge and practices on the safe handling of CDs among nurses working in the Oncology unit at tertiary teaching hospitals in Addis Ababa, Ethiopia. The result of this study will contribute important baseline data for policymakers, health care managers and medical directors, nurses, and other stakeholders especially to develop guidelines/protocol that facilitates safe handling of CDs among Oncology Nurses.

\section{Methods and Materials \\ Study Setting and Design}

This cross-sectional study was carried out to assess knowledge and practices of safe handling of CDs in selected tertiary teaching hospitals in Addis Ababa in April 2019, the capital city of Ethiopia. Among 13 governmental hospitals in the city, Tikur Anbesa Specialized Hospitals (TASH) and St. Paul's Hospital Millennium Medical College (SPHMMC) were considered for this study 
because CDs have been administered by Oncology nurses only at these governmental hospitals in Ethiopia.

\section{Population and Sampling}

All Nurses working in Tikur Anbesa Specialized Hospital and St. Paul's Hospital Millennium Medical College were the source population while all the nurses working in oncology units of both hospitals in the city who met the inclusion criteria were the study population. Purposive sampling was used to select the sample. From the 85 nurses working in oncology units of the two hospitals, we included 77oncology nurses having at least one year of work experience, willing to participate in the study, and who were available during the data collection period. However, we exclude those oncology nurses on annual and maternity leaves.

\section{Variables of the Study}

Knowledge and practices of CD handling are dependent variables, and the independent variables include sex, age in years, marital status, educational level, work experience, profession, ever-attended training, availability, and use of personal protective equipment.

\section{Operational Definitions Knowledge}

We measured nurses' knowledge of safe handling of cytotoxic drugs using 15 questions. The total knowledge score ranges from zero to fifteen. Each correctly answered question provided a score of one (1) while incorrectly answered question assigned a score of zero (0).

\section{Practice}

We measured nurses' practice on the safe handling of cytotoxic drugs using 20 Likert scale type items. Each item has three response options with values of zero $(0)=$ never at all, one $(1)=$ sometimes, and two $(2)=$ always. The total score of the scale ranges from zero ( 0 ) to forty (40). A lower score would reflect poor knowledge and practices for the safe handling of CDs.

\section{Cytotoxic}

It is a substance or agent synonymous with antineoplastic agents and anticancer agents.

\section{Handling}

It involves receiving, processing, planning and compounding, administration, and cleaning, and disposal of CDs.

\section{Cytotoxic Wastes}

These are wastes associated with cytotoxic drugs that contain chemicals that are toxic to the cells includes materials that are contaminated by cytotoxic drugs, drug administration equipment (swabs and IV drip sets), any items that have been contaminated with cytotoxic materials, residue (blister packs and unopened medicine vials), PPE such as gowns and gloves, empty bags or patient excreta.

\section{Disposal of Wastes}

Defines as disposal of cytotoxic wastes. The most acceptable and safest way to dispose of cytotoxic waste is through incineration.

\section{Personal Protective Equipment (PPE)}

Includes Gloves, N-95 Masks, Gown/Apron, Eye protection (Goggles), head covers, shoe covers, and biological safety cabinet (BSC).

\section{Data Collection and Management}

The authors used a structured, pre-tested self-administered questionnaire to collect data. The questionnaire was adapted from previous literature ${ }^{15,19,30,32}$ comprising of three major sections, namely, section one composed of demographic data of the nurses such as age, sex, educational, marital status, total years' work experience, and training course on chemotherapy. Section two and three consisted of safe handling knowledge and practices of CDs respectively and the availability and utilization of Personal Protective Equipment (PPE). We also recruited two BSc Nurses to distribute and return the questionnaires.

Quality control was considered starting from the questionnaire design until the analysis process. It was pretested, and data collection facilitators were trained about the purpose of the study and ethical issues in the process of data filling. We supervised data collection processes. Before data entry, principal investigators checked for completeness of the data daily.

\section{Data Processing and Analysis}

EpiData software version 4.2.0.0 was used for data entry and then we exported data to SPSS version 23.0 for computing, recording, and statistical analysis. We performed ranges and means with standard deviations (SD) for continuous variables, and frequencies and percentages for categorical variables to articulate the descriptive results of the study. Data were summarized using frequency tables and text descriptions. Multiple linear regression was done to test the 
association between knowledge/practice about CD handling and independent variables. A variable with a $p$-value of $\leq$ 0.05 with a $95 \%$ uncertainty interval was treated as a significant factor for the knowledge/practice of safe handling of CDs.

\section{Ethical Considerations}

After we informed participants about the objective of the study, informed written consent was obtained from all study participants. The data was kept in a secure place and insured confidentiality by not recording names or any personal identifier of the participants.

\section{Results}

\section{Demographic Characteristics and Experience}

A total number of 77 nurses participated in this study. Table 1 shows the demographic characteristics, work

Table I Sociodemographic Characteristics and Work Experiences Among Oncology Nurses at Tertiary Teaching Hospitals in Addis Ababa, Ethiopia

\begin{tabular}{|l|l|l|}
\hline Variable & Frequency (N) & Percentage (\%) \\
\hline Sex & & \\
Male & 23 & 29.9 \\
Female & 54 & 70.1 \\
\hline Age in years & & \\
22 to 29 & 49 & 63.6 \\
30 to 39 & 23 & 29.9 \\
40 to 50 & 5 & 6.5 \\
\hline Marital status & & \\
Married & 39 & 50.6 \\
Single & 38 & 49.4 \\
\hline Educational achievement & & \\
Diploma & 2 & 2.6 \\
Bachelor's Degree & 68 & 88.3 \\
Master's Degree & 7 & 9.1 \\
\hline Place of work & & \\
Medical ward & 20 & 26 \\
Oncology ward & 19 & 24.7 \\
Oncology outpatient department & 16 & 20.8 \\
Hematology department & 22 & 28.5 \\
\hline Work experience (in years) & & 65.0 \\
I to 3 & 27 & \\
$\geq 4$ & 50 & 58.8 \\
\hline Had training on chemotherapy & & \\
Yes & 51 & \\
No & & \\
\hline
\end{tabular}

experience, and training of the study participants. The mean age of the participants was $29.4( \pm 5.2 \mathrm{SD})$ years ranging from 22 to 50 . Most of the participants were (70.1\%) female, in the age category of 22 to 29 (63.6\%), married (50.6\%), had a bachelor's degree in Nursing $(88.3 \%)$, and had not get training session (68.8\%). Nearly, two-thirds $(65.0 \%)$ of the nurse had more than 4 years' work experience (mean $5.3 \pm 4.3 \mathrm{SD}$ ).

\section{Knowledge About Safe Handling of Cytotoxic Drugs (CDs)}

The mean score of the nurse's knowledge was $7.80( \pm 2.20$ $\mathrm{SD})$. Of the total, 59 (76.6\%) nurses heard about CDs. Only $23(29.9 \%), 24(31.2 \%)$, and $20(26.0 \%)$ of the participants heard about alkylating agent, antitumor, and antimetabolite chemotherapy drugs, respectively. The majority of the respondents $(89.6 \%)$ reported that CDs are hazardous to health and $58.4 \%$ of the respondents reported that CDs are carcinogenic.

The supplementary material file (Table S1) depicts that almost all respondents reported (97.4\%) they could minimize by taking safety precautions. Sixty-nine (89.6\%) of the respondents reported they take safety precautions during the preparation and administration of chemotherapy, and disposal of wastes of CDs. Seventy (90.9\%) nurses answered that they must wear PPE including gown, gloves, masks, goggles, headcover, and shoe cover. Forty-four (57.1\%) and 27 (35.1\%) of the respondents correctly reported of preparation of CDs in biological safety cabinets and well-ventilated separate rooms respectively. Thirty-seven (48.1\%) of the respondents were used disposable syringes without Luer-lock fittings during cytotoxic drug administration. Sixty-two $(80.5 \%)$ of the respondents reported that nurses should expel air from a syringe full of CDs in safety cabinet. Forty-eight $(62.3 \%)$ respondents reported that cytotoxic drugs are stored in a cool dark separate place. The immediate action was correctly taken by $85.7 \%$ of nurses if cytotoxic drugs contaminate their eyes and were reported to be immediate rinsing with tap water. Needle and syringes should be disposed of in punctureproof containers after capped or crushed and in plastic bags labeled with hazardous wastes as correctly reported by $37.7 \%$ and $35.1 \%$ of the respondents, respectively. The best method for disposing of hazardous waste was correctly reported to be incineration by $36(46.8 \%)$ nurses (see Table S1). 


\section{Utilization of Personal Protective}

\section{Equipment (PPE)}

Respondents were asked for the availability of PPE and how often they wore specific types of PPE while preparing and administering chemotherapy drugs to patients (Table 2). Out of the total, $56(72.7 \%), 32(41 \%)$, and $15(19.5 \%)$ of nurses reported that gloves, N-95 masks, and goggles are always available. Moreover, 44 (57.1\%) and 73 (94.8\%) of nurses said they never got their head and shoe covers respectively. Fifty-six (72.7\%) of nurses stated they wore gloves always when handling CDs. As shown in Table 2, 28 (36.4\%), 36 (46.7\%), and $42(54.5 \%)$ of the respondents have always used an apron, N-95 masks, and biological safety cabinet respectively. However, 26 (33.8\%), 36 (46.8\%), and 72

Table 2 Availability and Utilization of PPE* Among Oncology Nurses at Tertiary Teaching Hospitals in Addis Ababa, Ethiopia

\begin{tabular}{|l|l|l|l|}
\hline \multirow{2}{*}{ Variable } & Always & Sometimes & Never \\
\cline { 2 - 4 } & N (\%) & N (\%) & N (\%) \\
\hline Availability of Glove & $56(72.7)$ & $21(27.3)$ & - \\
Availability of N-95 Mask & $32(41.4)$ & $30(39.0)$ & $15(19.5)$ \\
Availability of Goggles & $15(19.5)$ & $37(48.0)$ & $25(32.5)$ \\
Availability of Apron & $27(35.0)$ & $34(44.2)$ & $16(20.8)$ \\
Availability of Head cover & $10(13.0)$ & $23(29.9)$ & $44(57.1)$ \\
Availability of Shoe cover & - & $4(5.2)$ & $73(94.8)$ \\
Use of Glove & $56(72.7)$ & $21(27.3)$ & $13(16.9)$ \\
Use of N-95 Mask & $36(46.7)$ & $28(36.4)$ & $26(33.8)$ \\
Use of Goggles & $13(16.9)$ & $38(49.3)$ & $12(15.6)$ \\
Use of Apron & $28(36.4)$ & $37(48.0)$ & $36(46.8)$ \\
Use of Head cover & $16(20.8)$ & $25(32.5)$ & $72(93.5)$ \\
Use of Shoe cover & - & $5(6.5)$ & $14(18,2)$ \\
Use of Biological Safety Cabinet (BSC) & $42(54.5)$ & $21(27.3)$ & \\
\hline
\end{tabular}

Note: $\mathrm{N}$ stands for frequency and \% is the percentage.

Abbreviation: *Personal protective equipment.

Table 3 Safe Handling Practices of CD* Among Oncology Nurses at Tertiary Teaching Hospitals in Addis Ababa, Ethiopia

\begin{tabular}{|c|c|c|c|}
\hline \multirow[t]{2}{*}{ Variable } & Always & Sometimes & Never \\
\hline & $\mathbf{N}(\%)$ & $\mathbf{N}(\%)$ & $\mathbf{N}(\%)$ \\
\hline Nurses wear protective clothing's during exposure to CDs & $43(55.8)$ & $31(40.3)$ & $3(3.9)$ \\
\hline Nurses take safety precautions during handling CDs & $40(51.9)$ & $31(40.3)$ & $6(7.8)$ \\
\hline Nurses prepare CDs in vertical safety cabinet & $42(54.5)$ & $21(27.3)$ & $14(18.2)$ \\
\hline Nurses wear protective clothes while changing IV fluids' containing CDs & $19(24.6)$ & $34(44.2)$ & $24(31.2)$ \\
\hline Nurses use needles as venting devices in IV bottle & $23(29.8)$ & $27(35.1)$ & $27(35.1)$ \\
\hline Nurses use disposable syringe with Luer-lock to prepare and administer CDs & $8(10.4)$ & $14(18.2)$ & $55(71.4)$ \\
\hline Nurses teach patient/visitors about the safe handling of body wastage of patient's receiving CDs & $32(41.6)$ & $39(50.6)$ & $6(7.8)$ \\
\hline Nurses dispose contaminated needles in puncture proof container & $47(61.0)$ & $19(24.7)$ & II (14.3) \\
\hline Nurses guide ward attendants in taking safety precaution while collecting hazardous wastes of CDs & $32(41.6)$ & $29(37.7)$ & $16(20.7)$ \\
\hline Nurses store hazardous CDs in a covered container & $23(29.9)$ & $26(33.8)$ & $28(36.3)$ \\
\hline Persons collecting hazardous wastes take precautions while transferring wastes from ward to incineration & $27(35.1)$ & $33(42.9)$ & $17(22.1)$ \\
\hline Nurses prepare CDs in nursing station & $13(16.9)$ & $9(11.7)$ & $55(71.4)$ \\
\hline Nurses prepare CDs at patient's bedside & $8(10.3)$ & $13(16.9)$ & $56(72.7)$ \\
\hline Nurses drink coffee at CDs' preparation area & $2(2.6)$ & $6(7.8)$ & $69(89.6)$ \\
\hline Nurses expel air from syringes' containing CDs in an open area & $17(22.1)$ & $18(23.4)$ & $42(54.5)$ \\
\hline Nurses transfer prepared CDs from one place to another with bare-hand & $8(10.4)$ & $17(22.1)$ & $52(67.5)$ \\
\hline Nurses wipe out small spills on the skin with tissue paper immediately & $20(26.0)$ & $33(42.9)$ & $24(31.2)$ \\
\hline Nurses use a damp cloth for managing spillage of powder from CDs & $8(10.4)$ & $33(42.9)$ & $36(46.7)$ \\
\hline Nurses store hazardous drug's wastes together with other wastes & $23(29.9)$ & $19(24.7)$ & $35(45.4)$ \\
\hline Hazardous wastes of CDs are disposed of through incineration & $8(10.4)$ & $18(23.4)$ & $5 I(66.2)$ \\
\hline
\end{tabular}

Notes: *Cytotoxic drug; $\mathrm{N}$ stands for frequency and \% for percentage. 
(93.5\%) of nurses were reported they never used goggles, head, and shoe covers respectively. Gloves and masks were more available and consistently used equipment in this study.

\section{Practice on the Safe Handling of Cytotoxic Drugs}

The mean score of nurses on practice on safe handling cytotoxic drugs was $22.1( \pm 5.50 \mathrm{SD})$. Of all nurses, 43 $(55.8 \%)$ of them always wear protective clothing when exposed to CDs and 40 (51.9\%) of them always take safety precautions during handling CDs. Forty-two (54.5\%) and 13 (16.9\%) of the respondents were always prepared CDs in vertical safety cabinets and nursing station respectively. Only 19 (24.6\%) of the respondents were always wearing protective clothing at the time of changing intravenous (IV) fluids' containing CDs. Nevertheless, 24 (31.2\%) of the respondents never wore protective clothes at the time of changing IV fluids' containing CDs. Twenty-seven (35.1\%) and 55 (71.4\%) of the respondents were never used needles as venting devices in IV bottles and Luer-lock respectively. Eight (10.4\%) of the respondents were always transferred prepared CDs from one place to another with bare-hand. Forty-seven (61.0\%) nurses were always disposed of contaminated needles in a puncture-proof container while $11(14.3 \%)$ of them never do. Only 23 (29.9\%) and 8 (10.4\%) of the respondents were always stored hazardous drug wastes in a covered container and dispose of incineration respectively (Table 3).

\section{Factors Affecting the Respondents' Knowledge and Practice}

Multiple linear regression was used to assess how well the independent variables predict the knowledge (Table 4) and practice (Table 5) of CDs handling among nurses working in hospitals. Besides, the test described the extent of variance that can be explained by the independent variables, and the best predictor variable for the two dependent variables. Accordingly, after the variance explained by all other variables in the model were controlled, Nurses who had not heard about CDs had an average knowledge score 0.33 points lower than nurses who had heard about CDs (p-value $<0.01$ ) indicating that it uniquely explains $9 \%$ of the variance in total knowledge scores.

Similarly, nurses who have scored higher knowledge points were had 0.33 points more practice score of safe CD handling than those who had lower knowledge score $(\mathrm{p}<0.05)$. Moreover, married nurses had average safe CDs handling practice score 0.27 points lower than nurses who had not married $(p<0.05)$. Knowledge makes the strongest unique contribution to explaining the practice, demonstrating that it uniquely explains $8 \%$ of the variance in the total practice scores.

\section{Discussion}

The current study aimed to examine the knowledge and practice of Oncology Nurses regarding the safe handling of cytotoxic drugs (appears to be the first local investigation) in oncology units of two tertiary teaching hospitals in Addis Ababa, Ethiopia. The mean score of the Nurse's knowledge was $7.82( \pm 2.22 \mathrm{SD})$. This is lower compared to findings of studies conducted in Egypt $(19.05 \pm 4.80$ out of 26), Nepal ( $61.32 \pm 17.12$ out of 100$)$, the United States $(10.16 \pm 1.46$ SD out of 12), Iran $(9.43 \pm 1.50 \mathrm{SD}$ out of 12); Malaysia (73.40 $\pm 8.88 \mathrm{SD}$ out of 100) and Cyprus (participants' knowledge was 79.43 out of 100). ${ }^{18,24,26,33-35}$ The differences may be due to inadequate in-service training for Oncology nurses concerning

Table 4 Multiple Linear Regression Analysis Predicting Knowledge of CD* Handling Among Oncology Nurses at Tertiary Teaching Hospitals in Addis Ababa, Ethiopia

\begin{tabular}{|c|c|c|c|c|c|c|}
\hline \multirow[t]{2}{*}{ Variable } & \multirow[t]{2}{*}{ Beta (Stand') } & \multirow[t]{2}{*}{ P-value } & \multicolumn{2}{|c|}{ Confidence Interval } & \multicolumn{2}{|c|}{ Collinearity Statistics } \\
\hline & & & Lower & Upper & Tolerance & VIF@ \\
\hline Gender (F) & 0.035 & 0.754 & -0.911 & 1.252 & 0.855 & 1.170 \\
\hline Education (Diploma) & 0.142 & 0.180 & -0.934 & 4.885 & 0.977 & 1.023 \\
\hline Education (MSc) & 0.153 & 0.171 & -0.520 & $2.87 \mid$ & 0.881 & 1.135 \\
\hline Marital (single) & -0.017 & 0.891 & -1.145 & 0.997 & 0.730 & 1.370 \\
\hline Had training (no) & -0.096 & 0.422 & -1.553 & 0.658 & 0.766 & 1.306 \\
\hline Heard about CDs (No) & -0.328 & 0.006 & -2.909 & -0.521 & 0.820 & 1.220 \\
\hline Age & 0.011 & 0.949 & -0.138 & 0.147 & 0.391 & 2.555 \\
\hline Work experience & -0.230 & 0.166 & -0.292 & 0.051 & 0.397 & 2.517 \\
\hline
\end{tabular}

Notes: Variable with bold is variable with a p-value less than 0.05 that has a significant association with the outcome variable. $*$ Cytotoxic drug. Abbreviation: @VIF, Variance inflation factor. 
Table 5 Multiple Linear Regression Analysis Predicting the Practice of CD* Handling Among Oncology Nurses at Tertiary Teaching Hospitals in Addis Ababa, Ethiopia

\begin{tabular}{|l|l|l|l|l|l|l|}
\hline Variable & \multirow{2}{*}{ Beta (Stand') } & \multirow{2}{*}{ P-value } & \multicolumn{2}{l|}{ Confidence Interval } & \multicolumn{2}{l|}{ Collinearity Statistics } \\
\cline { 3 - 6 } & & & Lower & Upper & Tolerance & VIF@ \\
\hline Gender (F) & -0.178 & 0.129 & -4.953 & 0.646 & 0.853 & 1.172 \\
Education (Diploma) & -0.032 & 0.771 & -8.745 & 6.515 & 0.951 & 1.051 \\
Education (MSc) & 0.102 & 0.383 & -2.490 & 6.408 & 0.857 & 1.167 \\
Marital (single) & $-\mathbf{0 . 2 7 0}$ & $\mathbf{0 . 0 3 5}$ & $-\mathbf{5 . 7 5 9}$ & $-\mathbf{0 . 2 1 6}$ & $\mathbf{0 . 7 3 0}$ & $\mathbf{1 . 3 7 0}$ \\
Had training (no) & -0.138 & 0.267 & -4.486 & 1.262 & 0.759 & 1.318 \\
Have heard about CDs (Yes) & -0.097 & 0.445 & -4.531 & 2.010 & 0.731 & 1.367 \\
Age & -0.274 & 0.115 & -0.664 & 0.074 & 0.391 & 2.556 \\
Work experience & 0.155 & 0.372 & -0.248 & 0.653 & 0.386 & $\mathbf{0 . 7 2 9}$ \\
Knowledge & $\mathbf{0 . 3 2 5}$ & $\mathbf{0 . 0 1 2}$ & $\mathbf{0 . 1 8 4}$ & $\mathbf{1 . 4 3 6}$ & $\mathbf{0 . 3 7}$ \\
\hline
\end{tabular}

Notes: Variables with bold are variables with a p-value less than 0.05 that have a significant association with the outcome variable. ${ }^{*}$ Cytotoxic drug. Abbreviation: @VIF, Variance inflation factor.

the handling of cytotoxic drugs or variation in data collection tools. Besides, the finding of the Malaysian study is post-intervention. Moreover, most of the nurses were without training sessions in the current study. This lack of knowledge on preventive measures is of concern because it increases the nurses' unsafe behavior.

In our study, the mean practice score was $(22.1 \pm 5.50$ SD out of 40). This result is comparable with that of Hospitals of Urmia University, Iran (13.41 \pm 4.70 SD out of 23). ${ }^{24}$ However, it is lower compared to the findings of studies conducted in Egypt $(8.87 \pm 1.35$ out of 12$){ }^{33}$ in Shiraz hospitals, South of Iran $(21.10 \pm 3.76$ SD out of $31),{ }^{31}$ and Malaysia $(15.30 \pm 2.55 \mathrm{SD}$ out of 20$) .{ }^{35}$ This may be due to the effects of training given for nurses and variation in the availability of PPE. While the Malaysian study used an interventional design, we used a crosssectional design in the study. Less availability and low use of the PPE and low-level knowledge were observed in this study; which showed also inadequate practice grade.

This study revealed that nearly $69 \%$ of nurses reported the lack of training program on the handling of cytotoxic drugs at their workplaces, which is similar to findings of studies conducted in South Egypt and Erbil city. ${ }^{3,36}$ This current result is different from the results of studies conducted in Hospitals of Urmia University, Iran, ${ }^{24}$ Egypt, ${ }^{33}$ and Kenya ${ }^{15}$ in which about three-fourth, more than half, and $40.37 \%$ of the nurses had previous training respectively. However, the present result is higher than a study done in Shiraz hospitals, South of Iran. ${ }^{31}$ This could be due to differences in hospitals' setup and rule and regulation or safety policy on the safe handling of cytotoxic drugs. The difference could also be attributed to limited resources for the training of healthcare workers. Moreover, workshops and other training forums are important for Oncology Nurse about the safe handling of CDs in hospitals.

In this study, about three-fourths of the nurses used gloves as a safety precaution, less than half-used masks and about one-third used protective aprons consistently during preparing CDs. Very few used goggles and head covers and almost none used shoe covers consistently. A study conducted in Turkey ${ }^{25}$ reported that $96.9 \%$, $78.1 \%, 56.3 \%$, and only $3.1 \%$ of nurses used gloves, masks, protective aprons, and goggles while preparing CDs respectively. The current finding is lower for gloves, masks, and protective aprons use during preparing CDs compared to the Turkey study but higher for goggles. None used all of the protective equipment while $62 \%$ used gloves and surgical masks together and $92 \%$ used gloves during CDs therapy preparation in the Nepal study. ${ }^{18}$ The current finding is lower for gloves use while preparing CDs compared to Nepal's study. However, the result is higher compared to a study conducted in Egypt ${ }^{27}$ that reported there was no use of gloves and surgical masks by study nurses but a very small number of them used all of the recommended protective equipment when handling CDs. This difference might be due to the variation in the availability of PPE.

Similarly, another study conducted in Shiraz, Iran reported that approximately $60 \%$ of nurses used all PPE, which is higher than the finding of the current study. ${ }^{23}$ Almost half of the nurses used basic protective equipment including gowns, masks, goggles, and gloves during 
medication preparation through the use of this equipment during the administration and disposal of CDs was insufficient as reported by other studies conducted in Shiraz hospitals, South of Iran. ${ }^{31}$ The present study finding is also lower compared to a study conducted in Kenya ${ }^{15}$ that reported a high level in the use of PPE and Cyprus ${ }^{26}$ that reported high levels of compliance with the use of gloves (95.4\%) and protective gown (84.5\%) during reconstitution of CDs. This difference might be due to the difference in the availability of PPE. Gloves and masks were more available and consistently used in this study, nurses did not take sufficient precautions to protect their eyes, head area, or body. This implies that nurses were not using all types of PPE consistently. Yet consistent use of all PPE minimizes the risk of exposure of nurses during the handling of cytotoxic drugs.

This study revealed that participants who have not heard about the CDs previously had negatively influenced the knowledge of nurses on the safe handling of CDs. Also, none of the demographic variables was significantly associated with both knowledge and practices of handling CDs; the practice of married nurses was better than that of unmarried nurses. This reason might be that married nurses could be more responsible for themselves and their families. Similarly, a study conducted in Zagazig University hospitals, Egypt ${ }^{19}$ reported that nearly all socio-demographic data did not significantly affect a change of knowledge and performance. In contrarily, as reported by a study done in Tanta University Hospitals, Egypt, ${ }^{33}$ there were significant correlations between age, marital status, educational level, years of experience, and receiving training and total knowledge and practice score. Nevertheless, a study conducted in Saint Tukdoji Maharaj Cancer Hospital, Nagpur (India), highlighted coordinated education and training strategy for chemotherapy practice is warranted to underpin safe and effective practice in this area. ${ }^{37}$ The dissimilarities may be due to a lack of training that influenced both knowledge and practices.

This study indicated that the knowledge and practice of nurses on the safe handling of CDs has a significant relationship. Nurses who have scored higher knowledge points were more likely to practice safe CD handling. Similarly, a study conducted in Zagazig University Hospitals ${ }^{19}$ showed that there is a positive significant correlation between change of knowledge and change of practice (as knowledge improved, practice improved). A study in Pakistan reported also similar findings, the higher the nurses' knowledge the more they use the safety measures in their practices. ${ }^{29}$ Also, a study in Pakistan $^{22}$ reported registered nurses working in the oncology unit of a tertiary care hospital have limited knowledge about the handling of CDs, which affected their attitudes, and practices of handling CDs in their daily practices. Moreover, it is in agreement with the result of a study conducted in Seoul, Korea ${ }^{38}$ that reported positive relationships of knowledge and compliance with safe handling of CDs. However, the result of a study conducted in Erbil City, Iraq showed that there was a significant negative association between knowledge and practices. ${ }^{11}$

The results of the current study may be assumed to be an important addition to the existing body of knowledge, especially in the Ethiopian context as no previous research within the Oncology nursing population has been conducted in this field. The standard and valid questionnaires used in other studies were adapted, pretested, and used for this study. Although this is the first assessment of knowledge and practices of Ethiopian nurses concerning CD handling, it was based on a relatively small sample of oncology nurses working in oncology units. Our findings may not be representative of nurses working in other departments. Furthermore, the assessment of nurses' knowledge and practices of safe handling of CDs was based entirely on self-reporting, which may have led to an over-reporting. On the other hand, determining causality is impossible due to the nature of the study design used.

\section{Conclusions}

Nurses' knowledge and practice of safe handling of cytotoxic drugs are inadequate. Most nurses did not take training about the handling of chemotherapy. The lack of adequate training for the nurses was noticeable. The study indicated that nurses more consistently used gloves and masks as personal protective measures during the handling of CDs. Nevertheless, none used all the protective equipment altogether during handling (preparation, administration, and disposal) of CDs. The current finding is lower for gloves use while preparing Therefore, training, safety surveillance systems, supplying personal protective equipment, and developing standard practice guidelines for oncology nurses working in oncology centers are of paramount importance. 


\section{Abbreviations}

BSC, Biological Safety Cabinet; CDs, Cytotoxic Drugs; DNA, Deoxyribonucleic Acid; GLOBOCAN, Global Cancer Incidence Mortality and Prevalence; HCWs, Health Care Workers; HD, Hazardous Drug; PPE, Personal Protective Equipment; SPHMMC, Saint Paul Hospital Millennium Medical College; TASH, Tikur Anbesa Specialized Hospital.

\section{Data Sharing Statement}

Data will be shared upon reasonable request from the corresponding author.

\section{Ethical Approval}

Ethical clearance was obtained from institutional review boards of both Addis Ababa University, College of Health Sciences, School of Nursing and Midwifery, and St. Paul's Hospital Millennium Medical College. Above all, this study was carried out according to the Helsinki Declaration of Ethical Principles for Research. Besides, the School of Nursing and Midwifery of Tikur Anbessa Specialized Hospital (TASH), Addis Ababa University, wrote a support letter for both hospitals. After obtaining permission from the two hospitals, the data collection was started. The patient's identifiers, such as name, were not used in the research report or any other to maintain patient confidentiality.

\section{Acknowledgments}

The authors are indebted to Addis Ababa University for approval of the ethical clearance, the Tikur Anbessa Specialized Hospital (TASH), and St. Paul's Hospital Millennium Medical College for permitting us to collect data. The authors also forward their gratitude to data collectors, supervisors, and study participants.

\section{Author Contributions}

All authors made substantial contributions to conception and design, acquisition of data, or analysis and interpretation of data; took part in drafting the article or revising it critically for important intellectual content; agreed to submit to the current journal; gave final approval of the version to be published; and agree to be accountable for all aspects of the work.

\section{Funding}

There was no specific funding obtained for this study.

\section{Disclosure}

This manuscript and the data within it and the tables were derived from an original thesis of SA, which was for the fulfillment of the Master's program, not a degree by publication. The full thesis work (preprint) was archived in the institutional electronic repository of Addis Ababa University (http://etd.aau.edu.et/bitstream/handle/ 123456789/21434/Selamawit\%20asefa.pdf?sequence= $1 \&$ isAllowed=y). Any journal publication of the manuscript derived from this thesis does not violate the policy of Addis Ababa University and it has no role in the publication. The authors declare that they have no other potential conflicts of interest for this work.

\section{References}

1. Torre LA, Bray F, Siegel RL, Ferlay J, Lortet-Tieulent J, Jemal A. Global cancer statistics, 2012. CA Cancer J Clin. 2015;65(2):87-108. doi: $10.3322 /$ caac. 21262

2. Bray F, Ferlay J, Soerjomataram I, Siegel RL, Torre LA, Jemal A. Global cancer statistics 2018: GLOBOCAN estimates of incidence and mortality worldwide for 36 cancers in 185 countries. Am Cancer Soc CA Cancer J Clin. 2018;68:394-424. doi:10.3322/caac.21492

3. Mohamed NMA. Effect of designed nursing protocol on nurse's knowledge and practice regarding chemotherapy. Med J Cairo Univ. 2015;83(2):209-216.

4. Jemal A, Bray F, Forman D, et al. Cancer burden in Africa and opportunities for prevention. Cancer. 2012;118:4372-4384. doi:10.1002/cncr.27410

5. Woldeamanuel YW, Girma B, Teklu AM. Cancer in Ethiopia. Lancet Oncol. 2013;14(4):289-290. doi:10.1016/S1470-2045(12)70399-6

6. Tegegn HG, Reda HL, Tilahun Y Access to cancer medicine issues: implication for policy and practice in ethiopia. in: access to cancer medicine issues: implication for policy and practice in ethiopia [Internet]; 2020. Available from: https://ascopubs.org/go/authors/ open-accessforreuseterms. Accessed March 16, 2021

7. Federal Ministry of Health Ethiopia. Disease Prevention and Control Directorate. National Cancer Control Plan of Ethiopia 2016-2020. 2015.

8. Page R, Takimoto C. Principles of chemotherapy. In: Pazdur R, Coia LR, Hoskins WJ, Wagman LD, editors. Cancer Management: A Multidisciplinary Approach Medical, Surgical \& Radiation Oncology. New York: PRR; 2004:21-38.

9. Easty AC. Handling of hazardous drugs: risk prevention by personal protective equipment. Sharing Expertise. B. Braun Melsungen AG. Germany. 2018. 1-32 p.

10. Mohsen MM, Fareed ME. Chemotherapy safety protocol for oncology nurses: it's effect on their protective measures practices. World Acad Sci Eng Technol. 2013;7(9):529-537.

11. Esmail DH, Qadir CS, Mahmood EK, Osman GA, Omar YB. Safe handling knowledge and practices of chemotherapy among oncology nurses in Erbil City. Kufa J Nurs Sci. 2015.

12. Huff C. USP $<800>$ compliance: a hazardous drug safe handling PPE toolkit for infusion nurses. Doctor of Nursing Practice (DNP) Projects 163. 5-28. 2020.

13. Eedes DJ, Bailey B, Burger H. Chemotherapy administration standards and guidelines: the development of a resource document. $S A$ J Oncol. 2018;2:1-6.

14. Mitheu HK, Mwaura J, Kivuti-bitok LW. Assessment of institutional support on healthcare workers in safe handling of cytotoxic agents and related waste at Kenyatta National Hospital. Int J Heal Sci Res. 2019;9(9):127-136. 
15. Sheikh YA. Knowledge and practice on safe handling of cytotoxic drugs among health care workers at Kenyatta National. 2016.

16. Government of South Australia SH. Safe handing. cytotoxic drugs and related waste: a risk management guide for South Australian Health Services [Internet]; 2015. Available from: www.sahealth.sa. gov.au/hazardousdrugs. Accessed March 16, 2021.

17. Boiano JM, Steege AL, Sweeney MH. Adherence to safe handling guidelines by health care workers who administer antineoplastic drugs. HHS public access: author manuscript; available in PMC 2015 September 14. J Occup Env Hyg. 2015;11(11):728-740. doi:10.1080/15459624.2014.916809

18. Chaudhary R, Karn BK. Chemotherapy-knowledge and handling practice of nurses working in a Medical University of Nepal. J Cancer Ther. 2012;03(01):110-114. doi:10.4236/jct.2012.31014

19. Bolbol S, Hassan A, El-Naggar S, Zaitoun M. Role of occupational health and safety program in improving knowledge and practice among nurses exposed to chemotherapy at Zagazig University Hospitals. Egypt J Occup Med. 2016;40(2):219-235. doi:10.21608/ejom.2016.842

20. Kwon P. Guide for handling cytotoxic drugs and related waste. Qld Nurse. 1997;16(4):22.

21. Nwagbo SE, Ilesanmi RE, Ohaeri BM, Oluwatosin AO. Knowledge of chemotherapy and occupational safety measures among nurses in oncology units. J Clin Sci. 2017;14(3):131-137. doi:10.4103/jcls.jcls_88_16

22. Ali FB, Arif S, Pesnani F. Association of knowledge on the attitude and practice of registered nurses regarding handling of cytotoxic drugs in a Tertiary Care Hospital in Karachi Pakistan. Int $J$ Nov Res Healthc Nurs. 2015;2(3):73-76.

23. Momeni M, Daniel M, Askarian M. How do nurses manage their occupational exposure to cytotoxic drugs? A descriptive survey in chemotherapy settings, Shiraz, Iran. Int J Occup Env Med. 2013;4 (2):102-106.

24. Orujlu S, Habibzadeh H, Zare MJ, Hajaghazadeh M. Knowledge, attitude, and performance of oncology nurses handling antineoplastic drugs in hospitals of Urmia University, Iran. Int J Occup Hyg. 2016;14-21.

25. Unsar S, Professor B, Kurt S, Akgun Kostak M, Yaman R, Özcan M. Determination of antineoplastic drug exposure of nurses at a University Hospital [Internet]. Int J Caring Sc. 2016;9(1):314.

26. Kyprianou M, Kapsou M, Raftopoulos V, Soteriades ES. Knowledge, attitudes, and beliefs of Cypriot nurses on the handling of antineoplastic agents. Eur J Oncol Nurs. 2010;14(4):278-282. doi:10.1016/j. ejon.2010.01.025

27. Waheida SM, Abd-ELgaffar SI, Atia GA. Evaluation of handling practices of oncology nurses during chemotherapy preparation and administration in Menoufia Oncology Hospital [Internet]. Int J Novel Res Healthc Nurs. 2015;2(3):107-109.
28. Abdullah DAH, Rasheed OH. Nursing staff knowledge regarding safe chemotherapy administration at oncology center in Kirkuk City. Kirkuk Univ J. 2018;13(1):144-155. doi:10.32894/ kujss.2018.142401

29. Khan N, ZulfiqnarAli KK, Ali TS. Assessment of knowledge, skill, and attitude of oncology nurses in chemotherapy administration in tertiary hospital Pakistan. Open $J$ Nurs. 2012;2(02):97-103. doi:10.4236/ojn.2012.22015

30. Ibrahim A, Habiba AE, Zein Eldin YK, Ibrahem EM. Oncology nurses' knowledge and practises regarding handling hazardous drugs: developing procedure manual for safe handling of hazardous drugs. Drugs. 2018;7(2):1-11.

31. Abbasi K, Maryam H, Abolfazl M, et al. Protection behaviors for cytotoxic drugs in oncology nurses of chemotherapy centers in Shiraz hospitals, South of Iran. Indian J Med Paediatr Oncol. 2016;37 (4):227-231. doi:10.4103/0971-5851.195748

32. Shrestha D, Lama S, Badu A, Mandal GN. Impact of educational intervention on knowledge regarding safe handling of cytotoxic drugs among the nursing personnel working in BPKIHS. Impact Educ Interv Heal Renaiss. 2015;13(1):13-22.

33. Zayed H, Saied S, El-Sallamy R, Shehata W. Knowledge, attitudes, and practices of cytotoxic drugs among oncology nurses in Tanta University Hospitals. Egypt J Occup Med. 2019;43(1):75-92. doi: $10.21608 /$ ejom. 2019.25119

34. Callahan A, Ames NJ, Manning ML, Touchton-Leonard K, Wallen GR, Wallen G. Factors influencing nurses' use of hazardous drug safe-handling precautions. Oncol Nurs Forum. 2016;43(3):1-9. doi:10.1188/16.ONF.43-03AP

35. Keat CH, Sooaid NS, Yun CY, Sriraman M. Improving safety-related knowledge, attitude and practices of nurses handling cytotoxic anticancer drug: pharmacists' experience in a general hospital, Malaysia. Asian Pacific J Cancer Prev. 2013;14(1):69-73. doi:10.7314/ APJCP.2013.14.1.69

36. Filip B, Marie-Jeanne H, Margareta W. Safe handling of antineoplastic drugs at a Public Hospital in Guangzhou, China: an observational study in clinical practice. 2016.

37. Kumari D. Assess the practice regarding safety measures used by nurses while administering chemotherapy drugs. Biomed J Sci Tech Res. 2018;2(1):2307-2310.

38. Yun JH, Park JY. Oncology nurses' knowledge of safety guidelines and compliance with safe handling of antineoplastic agents in a Tertiary Hospital. Asian Oncol Nurs. 2016;16(4):251. doi:10.5388/aon.2016.16.4.251
Drug, Healthcare and Patient Safety

\section{Publish your work in this journal}

Drug, Healthcare and Patient Safety is an international, peer-reviewed open-access journal exploring patient safety issues in the healthcare continuum from diagnostic and screening interventions through to treatment, drug therapy and surgery. The journal is characterized by the rapid reporting of reviews, original research, clinical, epidemiological and post-marketing surveillance studies, risk management, health literacy and educational programs across all areas of healthcare delivery. The manuscript management system is completely online and includes a very quick and fair peer-review system. Visit $\mathrm{http}: / /$ www.dovepress.com/testimonials.php to read real quotes from published authors. 